\title{
Interpersonal Relationship Marketing: Reciprocity in Buyer-Seller Dyad with Customer Gratitude as Mediator
}

\author{
Muhammad Ahmad * $\quad$ Mirza Ashfaq Ahmed ${ }^{\dagger} \quad$ Muhammad Anwar ul Haq ${ }^{\ddagger}$
}

\begin{abstract}
This research examines relationships among customer focal antecedents, seller focal antecedents, customers feeling of gratitude, and norms of reciprocity. The two-fold objectives of this research are; 1. To investigate role of customer focal and seller focal antecedents in development of reciprocity; 2. To analyze mediating role of customers feelings of gratitude in development of norms of reciprocity. The proposed hypotheses are tested with dyadic data set. The data is collected from both parties (buyer and seller) in the relationship from multiple sectors e.g., Food, Apparel, Financial, Medical and Travel agents. The dyadic data is analyzed with Partial least square structural equation modeling (PLS-SEM), because the nature of the data supports this analysis technique. The results highlight that both customer focal and seller focal antecedents have positive impact on customers' feelings of gratitude; additionally, customer focal antecedents directly leads to norms of reciprocity whereas seller focal antecedents leads to norms of reciprocity via feelings of gratitude as mediator. The research results provide fundamental support to interpersonal relationship marketing model. Theoretically this research validates and extends the interpersonal relationship marketing model by incorporating reinforcement theories of interpersonal attraction, and both buyer and seller perspective with dyadic data set; moreover, this research validate the thought that seller focal antecedents in relationship stimulate the customers emotions which is paid in form of reciprocal behavior and long-term relationship chain starts. From managerial perspective this research helps managers to understand the importance of seller customer focal and seller focal antecedents in relationships for reciprocal customers' behavior.
\end{abstract}

Keywords: Interpersonal relationship marketing, relationship benefits, relationship investment, gratitude, reciprocity, dyad, interpersonal attraction.

\section{Introduction}

In any business context, both buyers and sellers have different motivations to be engaged in committed long-term relationships (Sheth \& Parvatiyar, 1995). A wide array of factors such as reduction of choice, co-creation of value, humanizing element of brand (Ma, Tunney, \& Ferguson, 2017), and emotional attachment have been found to motivate a buyer to build and maintain the relationship with a seller. Seller interest in having committed relationships with their customers is not only prompted by the fact good relationship enhance

\footnotetext{
* University of Gujrat Ringgold Standard Institution, Gujrat, Pakistan.

${ }^{\dagger}$ University of Gujrat Ringgold Standard Institution, Gujrat, Pakistan.

$\ddagger$ University of Gujrat Ringgold Standard Institution, Gujrat, Pakistan.
} 
customers' propensity for repeat purchase (Sheth \& Parvatiyar, 1995); it is also critical for improving financial performance of seller. Sellers are required to maintain continuous relationship with customers in this highly competitive era. Through relationship practices sellers can create positive psychological ties with customers. All these factors motivate sellers to invest heavily on relationship activities to maintain and develop relationship with customers.

Relationship marketing is a process through which sellers build and endure relationships with customers. Contemporary researchers on relationship marketing have viewed relationship marketing as process-centric framework (Hütten, Salge, Niemand, \& Siems, 2018) and as a tenet to humanize brands (Ma et al., 2017). They have assessed relationship marketing readiness and studied online relationship formation (Kozlenkova, Palmatier, Fang, Xiao, \& Huang, 2017). They have also looked at group marketing theory in business relationship (Harmeling, Palmatier, Fang, \& Wang, 2017), midlife crises and revitalization of relationship marketing, service-dominant logic in understanding and expanding relationships and general relationship marketing theory. Attempts have also been made to synthesize relationship marketing into single marketing theory. The relationship marketing research developed into multiple areas e.g., relationship communication, relationship dynamic0 (Harmeling et al., 2017; Hollmann, Jarvis, \& Bitner, 2015), the role of relationships in relation to other key issues e.g., service recovery and service interactions. Moreover, from theoretical perspective there are an array of theories developed and applied in relationship marketing (Finch, O'Reilly, Hillenbrand, \& Abeza, 2015; Debnath, Datta, \& Mukhopadhyay, 2016). Theories from other social sciences disciplines e.g., psychology, evolutionary psychology, social psychology, social psychology, anthropology, and political science are applied and contribute in development of relationship marketing theory (Palmatier, Jarvis, Bechkoff, \& Kardes, 2009). This diverse nature of theory and thought in relationship marketing compel to synthesize literature.

The research in relationship marketing has identified number of seller focal antecedents and customer focal antecedents. However, Seller relationship investments (Huang, 2015) and customer relationship benefits (Chao, Chen, \& Yeh, 2015) are key ingredients in seller and customer relationship. Seller relationship investments are called seller focal antecedent and customer relationship benefits are marked as customer focal antecedent (Palmatier et al., 2009).

In this research customers feeling of gratitude is mediator. However, previous research in relationship marketing has focused on trust and commitment as mediators (Palmatier et al., 2009). The rationale behind gratitude based relationship assessment is to examine the relationship above economic and transactional benefits (Hasan, Lings, Neale, \& Mortimer, 2014). Moreover, relationship marketing research highlights the importance of gratitude as key factor to evoke customer decision making.

The research questions addressed here are: (1) what is role of customer focal and seller focal antecedents in development of norms of reciprocity, (2) How feelings of gratitude mediate between focal and seller focal antecedents in development of norms of reciprocity. Finally, this research contributes in the existing body of literature in the following ways: (1) It extends the interpersonal relationship marketing model by incorporating the both buyer and seller perspectives with interpersonal attraction, (2) In methodology, dyadic data is 
used to test the model, and (3) Interpersonal relationship marketing model is tested with multi sector data.

\section{Literature Review}

\section{Customer Focal Antecedent (Perceived Relationship Benefits)}

Customers may perceive value to relationship with sellers when they perceive benefits in the relationship (Morgan \& Hunt, 1994; Reynolds \& Beatty, 1999). Perceived relationship benefits is one of the most widely studied variable in relationship marketing (Palmatier et al., 2009) and marked as customer focal antecedent or customer focused antecedent. Customer focal antecedents are those factors that share the same perspective as the relational mediator. The benefits are delineated as social and functional benefits (Morgan \& Hunt, 1994), social, psychological, economic, and customization benefits (Gwinner, Gremler, \& Bitner, 1998), customized and differential benefits (Vargo \& Lusch, 2004), altruistic benefits (Becker-Olsen \& Hill, 2006), special treatment benefits, environmental benefits, social and confidence benefits, and sector specific benefits e.g., environments, awareness, image, and positioning of particular brand.

The empirical research in relationship marketing suggests customer relationship benefits as the foundation stone of customers-sellers commercial relationship (Morgan \& Hunt, 1994; Gwinner et al., 1998; Vargo \& Lusch, 2004; Becker-Olsen \& Hill, 2006). Moreover, customer relationship benefits are positive and significant predictor of relational mediators (Palmatier et al., 2009). Customer relationship benefits create customer feelings of gratitude. It is also empirically validated that gratitude is the emotional appreciation of benefits received (Cownie, 2016), benefits induce gratitude, and benefits influence gratitude. In this research, the customer relationship benefits are materialized as the customer perceived relationship benefits. It refers to benefits received by the customer from seller (Palmatier et al., 2009; Brun, Rajaobelina, \& Ricard, 2016). It is also noted that the receiver of the benefits may also reciprocate the benefits received. Therefore, the following hypotheses are outlined:

H1. Perceived relationship benefits have positive and significant impact on customer feelings of gratitude.

H2. Perceived relationship benefits have positive and significant impact on norms of reciprocity.

\section{Seller Focal Antecedent (Perceived Relationship Investments)}

Sellers employ multiple strategies to strengthen relationship with customers (Palmatier et al., 2009; Dewani, Sinha, \& Mathur, 2016; Hasan et al., 2014). Verma, Sharma, and Sheth (2016) studied the relationship in online retailing and found the relationship investments is one most widely researched seller focused antecedent. Palmatier et al. (2009) called the 
relationship investments as seller focal antecedent. Seller focal antecedents are delineated as a perspective opposite of that of the evaluation of the relational mediator. There are various types of investments that sellers may apply to strengthen relationship with their customers (Huang, 2015; Hasan et al., 2014). Seller relationship investments are defined as 'Consumer's perception of the extent to which a seller devotes resources, efforts, and attention aimed at maintaining or enhancing relationships with regular customers that do not have outside value and cannot be recovered if these relationships are terminated. Customer perception of relationship marketing investments'.

Empirical research suggests that relationship investments made by seller creates psychological ties with customers (Cropanzano \& Mitchell, 2005; Palmatier et al., 2009; Huang, 2015). Seller relationship investments is strong predictor of customer feelings of gratitude. Furthermore, investments made by the sellers are central to reciprocation principle (Bagozzi, 1995). From above illustrated theoretical backdrop following hypotheses are conceptualized:

H3. Perceived relationship investments have positive and significant impact on customer feelings of gratitude.

H4. Perceived relationship investments have positive and significant impact on norms of reciprocity.

\section{Customer Feelings of Gratitude}

Gratitude is derived from Latin word 'Gratia' which means being thankful. Gratitude is conceptualized as emotions generated after benefits received, gratitude as mood and as life orientation to appreciate others (Lambert, Graham, \& Fincham, 2009; Wood, Froh, \& Geraghty, 2010). Previous relationship marketing research has focused on trust and commitment as mediators. Contemporary relationship marketing researches promote the mediating role of gratitude (Jin, Line, \& Yoon, 2018).

In relationship marketing gratitude is marked as core emotional construct to understand the customer psychological ties with seller (Cropanzano \& Mitchell, 2005; Palmatier et al., 2009; Hasan et al., 2014). Empirical research suggests social and structural investments by sellers create customer gratitude. Similarly, customer relationship benefits also positively impact the customer feelings of gratitude (Hasan et al., 2014).

Gratitude is the emotional core of reciprocity (Huang, 2015) and enhance the customer motivation to reciprocate. Moreover, Gratitude mediates the relationship between antecedents and reciprocity. Gratitude is marked as important factor in commercial relationships and needs depth investigation in relationship formation. Therefore, the impact of gratitude on norms of reciprocity and gratitude as potential mediator between customer relationship benefits, seller relationship investments and norms of reciprocity is examined.

H5. Customer feelings of gratitude have positive and significant impact on norms of reciprocity. 
H6. Customer feelings of gratitude mediate between perceived relationship benefits and norms of reciprocity.

H7. Customer feelings of gratitude mediate between perceived relationship investments and norms of reciprocity.

\section{Norms of Reciprocity}

Reciprocity is defined as 'Internalized patterns of behaviors and feelings that regulate the balance of obligations between two exchange partners' (Palmatier et al., 2009). According to Bagozzi (1995), 'reciprocity is the core of marketing relationships'. Reciprocity creates high-quality relationships between the exchange partners (Griffith, Harvey, \& Lusch, 2006). Reciprocity is well acknowledged concept and applied in empirical relationship marketing research (Liu, Deligonul, Cavusgil, \& Chiou, 2018; Hoppner, Griffith, \& White, 2015). Reciprocity is an interpersonal construct. Philosophers, psychologist, and sociologist called it as fundamental to social stability and driver of successful relational exchange (Pervan, Bove, \& Johnson, 2009). Generally, reciprocity is referred to unidimensional concept (Paswan, Hirunyawipada, \& Iyer, 2017).

Palmatier et al. (2009) noted that, reciprocity and gratitude are genetically and socially hardwired into people that regulate and create balance in the social and moral system. The researchers in the field of relationship marketing advocate to study reciprocity (Hoppner et al., 2015; Pervan et al., 2009; Hasan et al., 2014). The debate that reciprocity as predictor or outcome factor is also very interesting in the relationship marketing literature. Most of the relationship marketing literature views reciprocity as independent or mediating concept; however the interpersonal relationship marketing model presented by Palmatier et al. (2009) highlighted reciprocity as dependent variable. According to Palmatier et al. (2009) reciprocity is generated after emotional debt. This emotional debt is referred to feelings of gratitude. Furthermore, it is also worthy to note that change in culture may have different implications and results with respect to reciprocity (Cropanzano \& Mitchell, 2005). In this research interpersonal relationship marketing model by Palmatier et al. (2009) is applied and reciprocity is analyzed as an outcome variable.

\section{Theoretical Framework}

Theoretical strength of this research is derived from interpersonal relationship marketing model (Palmatier et al., 2009) and interpersonal attraction theories of friendship development. According to interpersonal relationship marketing model, seller activities create customer feelings of gratitude and customers pay in form of reciprocal behavior (Palmatier et al., 2009). Furthermore, gratitude creates an ongoing cycle of reciprocation. Cropanzano and Mitchell (2005) highlighted that relationships passes through stages as ladder and gratitude is like mediating stage to go ahead in relationship.

Figure 1 
Conceptual Model

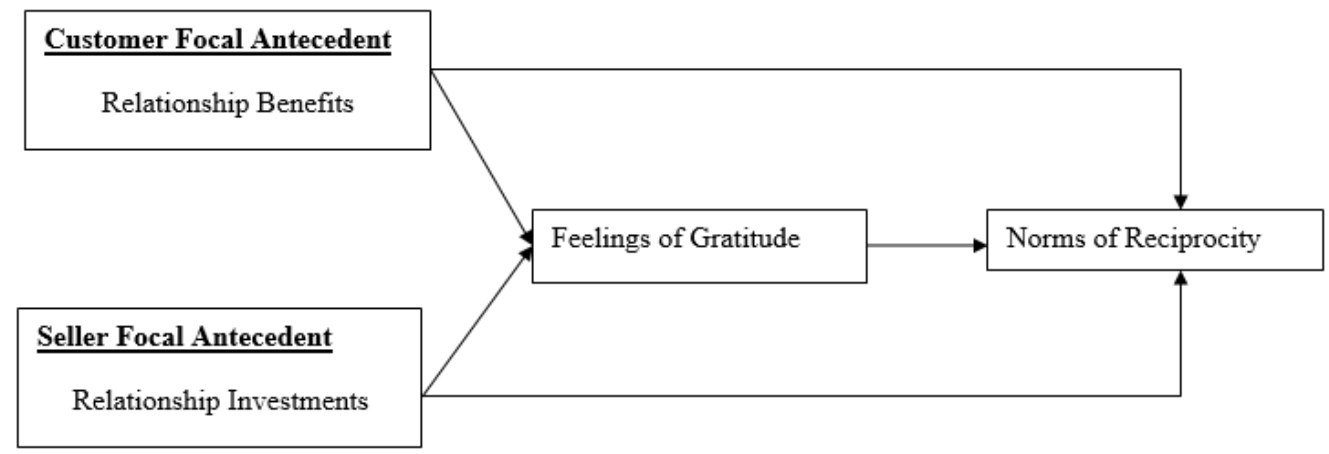

Perlman and Fehr (1986) highlight that in isolation we know much how forces in interpersonal attraction work but we have vague understanding in dyadic relationship. This research combines the reinforcement theory as customer focal antecedents (benefits and rewards) and seller focal antecedents as seller's effort to maintain the relationship. Interpersonal relationship model is applied to analyze reciprocal behavior in presence of gratitude to create balance (Perlman \& Fehr, 1986; Bagozzi, 1995). This complex theoretical inclusion is possible with dyadic data set e.g., from both parties (buyer and seller) for examining the relationship (Lussier \& Hartmann, 2017).

\section{Research Methodology}

This research follows hypotheses testing methodology with dyadic data set gathered with self administrated survey questionnaire from buyers and sellers. A dyadic data set have unique characteristics e.g., non-independence and Distinguishability; whereas a dyadic research design may be of standard dyadic design, Social Relations Model (SRM) design, and one-with-many design (Kenny, Kashy, \& Cook, 2006). This research is based on standard dyadic research design of buyer-seller B2C (Business to customer); where, for each seller one customer response is collected. The survey questionnaire is in two parts (Part A and B); part A for seller response and part B for customer response. Part-A questionnaire is designed to get demographic information (Gender, Designation, Job duration and Education) of seller's representative and his/her perspective of seller's relationship investment. Part-B is designed to get customers demographic information (Gender, Age, Occupation, Income, Education, Relationship duration with seller and Time since the last purchase) and record his/her perspective of relationship benefits and other variables of conceptual model.

\section{Sample}

The sample represents the following sectors: Food $(n=23)$, Apparel $(n=21)$, Financial $(\mathrm{n}=24)$, medical $(15)$ and travel agents $(\mathrm{n}=17)$. The quota sampling technique with conve- 
nience (from seller side) and systematic random (from the buyer side- until the respondent not match with the inclusion criteria mentioned below) is used to collect the data. The data is collected from hundred (100) buyer-seller dyads. From the seller side data is collected from chief executive officers (CEO) (e.g., CEO of travel agency) or the managers of the seller (e.g., bank's branch manager). This sample set represents almost all the population of the targeted sectors (operating in Gujrat, Punjab, Pakistan). The data is collected from only those CEO's and managers who have been part of the seller or owner of the business from last two years. This two years working with same organization is used as inclusion criteria. From the customer side; the data is collected from customers; a customer only qualifies when he/she is the customer of specific organization from last two years and he/she has visited the seller once in the last three months (buyer side inclusion criteria).

\section{Measures}

Established scales for all variables (Perceived relationship benefits, Perceived relationship investments, Customer feelings of gratitude, and Norms of reciprocity) with adaptation are used to collect data. Only those scales are used which reported higher reliabilities in the previous studies. Perceived relationship benefits was assessed using 4 items (Brun et al., 2016). Perceived relationship investments was measured with 3 items (Palmatier et al., 2009). Customer feelings of gratitude was measured with 3 items. Norms of reciprocity was assessed with 4 items. All items of above mentioned variables were measured using five-point Likert scale ranging from strongly disagree (1) to strongly agree (5).

\section{Data Analysis and Common Method Variance}

Hypotheses are tested using Partial least squares structural equation modeling (PLS-SEM) with SmartPLS version 3.2.1. PLS-SEM is variance based approach of SEM (Hair, Sarstedt, Ringle, \& Mena, 2012). The prominent justifications of using PLS-SEM are theory development and prediction (Hair, Ringle, \& Sarstedt, 2011), small sample size, and analysis regardless of reflective-formative constructs. Secondly, PLS-SEM seeks maximize the variance explained in the endogenous variables. It is also noted the popularity of PLS-SEM in the top marketing journals (Ahearne, MacKenzie, Podsakoff, Mathieu, \& Lam, 2010).

The reflective measures are used in this structural model. Reflective measures are linked to a variable through loading. These loading are bivariate correlations between measure and variable. For reflective model specification need both reliability and validity. Consistent to recommendations (Rungtusanatham, Miller, \& Boyer, 2014) and hypotheses of this research; both direct path (Relationship benefits and relationship investment to reciprocity) and indirect relationship paths (mediated path) (Relationship benefits and relationship investment leads to reciprocity via gratitude) are modeled. The mediation is examined with 5000 bias corrected bootsrapped estimates (Akter, Fosso Wamba, \& Dewan, 2017) due to its power to detect the mediated effect over the other conventional techniques (MacKinnon, Lockwood, \& Williams, 2004).

The predictors e.g., relationship investment and outcome e.g., reciprocity are assessed with data from different sources e.g., seller and customer. This way is quite impressive 
way to overcome method variance Common method variance (CMV); to collect data from multiple sources (Podsakoff, MacKenzie, Lee, \& Podsakoff, 2003). CMV is the variance based attribute that may leads to bias findings of correlation research by increasing or decreasing the strength of relationship between the variables (Podsakoff et al., 2003). To avoid the confusion and complexity separate questionnaire are formulated to tap the seller and customer responses. For the same respondent e.g., customer part of questionnaire; each variable appeared unrelated and separated.

\section{Results}

\section{Sample Characteristics}

Table-1 highlights the sample demographic composition; as data is of dyadic nature, so the both seller and buyer sample characteristics are given. Among the buyer sample there are 44 males and 56 females, whereas, with respect to seller's gender representation; there are 81 male and 19 female respondents. In terms of age, occupation, and monthly income only buyer's side demographic information is recorded and presented in table-1. According to aforementioned buyer's sample characteristics, data is collected from mostly student aged between 20-30 years. Both buyers and sellers representatives education is recorded and from both sides most the respondents are graduate and above graduate.

\section{Measurement Model}

Reliability and validity of measurement model is assessed. In table- 2 the outer loads of the measures of each variable and variation inflation factor (VIF) of each measure of variables in the conceptual model are presented. The qualification criteria for loadings is above .70; whereas benchmark value of VIF is below 5, that implies collinearity does not exist which may create estimation issue in PLS-SEM model. The loadings of all measures are above .70 and VIF are below 5 (except one measure of gratitude 2- this single measure VIF issue may not cause problem in analysis which proved in the model measurement which indicates the fitness of measures. The collinearity does not exist to cause issue in the PLS-SEM measurement model.

\section{Reliability and Validity}

For reflective measures, it is recommended to verify both reliability and validity. Traditionally, internal consistency is analyzed with Cronbach's alpha (Cronbach \& Meehl, 1955), whereas, composite reliability provides more appropriate measure of internal consistency; however, both alpha values and composite reliability are calculated in this research. The qualification criterion based on alpha values is above .70. The values of Cronbach's alpha and composite reliability are given in table- 4 . Values are above the benchmark. The validity is examined by noting discriminant and convergent validity. Support for convergent validity is drawn from the outer loading values in table- 2 and average variance extracted 


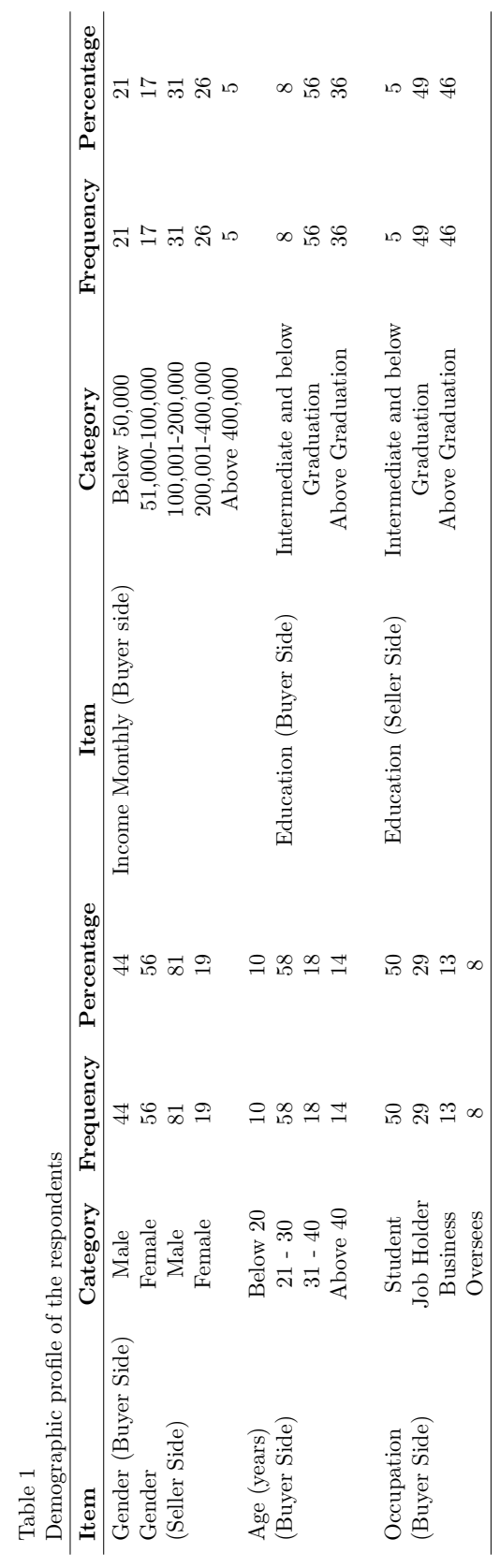


(AVE) in table-3; outer loads should be above .70 and AVE should be above .50, the criterion is met successfully as the outer loads are above .70 of each indicator of variable individually and AVE values are above .50 of each variable.

The discriminant validity is assessed with Fornell and Larcker (1981) criterion; which states that, square root of AVE (Given in parenthesis bold) should be higher than the correlation values of each variable.

Mean values and standard deviation are presented in table-4. Mean values of each construct are above 3 means the most of responses are towards agree and strongly agree. The standard deviation is well below 1 and almost all the variables have standard deviation of about .60 to .70 .

Table 2

Outer loadings and variation inflation factors (VIF)

\begin{tabular}{|c|c|c|c|c|c|}
\hline & $\begin{array}{l}\text { Relationship } \\
\text { Benefits }\end{array}$ & $\begin{array}{l}\text { Relationship } \\
\text { Investment }\end{array}$ & Gratitude & Reciprocity & $\begin{array}{c}\text { Variation Inflation } \\
\text { Factors (VIF) }\end{array}$ \\
\hline RB1 & 0.854 & & & & 2.518 \\
\hline RB 2 & 0.886 & & & & 2.978 \\
\hline RB 3 & 0.833 & & & & 2.133 \\
\hline $\mathrm{RB} 4$ & 0.781 & & & & 1.786 \\
\hline RI 1 & & 0.862 & & & 2.056 \\
\hline RI 2 & & 0.938 & & & 3.774 \\
\hline RI 3 & & 0.881 & & & 2.764 \\
\hline G 1 & & & 0.926 & & 4.502 \\
\hline G 2 & & & 0.959 & & 5.966 \\
\hline G 3 & & & 0.86 & & 2.252 \\
\hline R 1 & & & & 0.858 & 2.439 \\
\hline R 2 & & & & 0.862 & 2.297 \\
\hline R 3 & & & & 0.826 & 1.915 \\
\hline R 4 & & & & 0.864 & 2.251 \\
\hline
\end{tabular}

Table 3

Reliability and Average Variance Extracted (AVE)

\begin{tabular}{lccc}
\hline CONSTRUCT & $\begin{array}{c}\text { Composite } \\
\text { Reliability }\end{array}$ & $\begin{array}{c}\text { Cronbach's } \\
\text { Alpha }\end{array}$ & $\begin{array}{c}\text { Average Variance } \\
\text { Extracted (AVE) }\end{array}$ \\
\hline Relationship Benefit & 0.905 & 0.859 & $70.40 \%$ \\
Relationship Investment & 0.923 & 0.874 & $80.00 \%$ \\
Gratitude & 0.940 & 0.903 & $.83 .80 \%$ \\
Reciprocity & 0.914 & 0.874 & $72.60 \%$ \\
\hline
\end{tabular}

Table 4

Fornell-Larcker Criterion and Descriptive Statistics

\begin{tabular}{lcccc}
\hline CONSTRUCT & $\mathbf{1}$ & $\mathbf{2}$ & $\mathbf{3}$ & $\mathbf{4}$ \\
\hline 1.Relationship Benefit & -0.839 & & & \\
2. Relationship Investment & 0.627 & -0.894 & & \\
3. Gratitude & 0.563 & 0.700 & -0.916 & \\
4. Reciprocity & 0.657 & 0.613 & 0.695 & -0.852 \\
Mean & 4.020 & 3.690 & 3.800 & 3.660 \\
Standard Deviation & 0.590 & 0.710 & 0.760 & 0.680 \\
\hline
\end{tabular}




\section{Direct and Indirect Effects}

Table-5 and table- 6 display the direct effects and indirect effects of predictor variables on outcome variables. All direct effects are found significant and in line with direction, as they were hypothesized; except the effect of relationship investments on norms of reciprocity $(\beta=0.084, \mathrm{p}>0.05)$. This non-significance effect of relationship investments on norms of reciprocity caused rejection of $\mathrm{H} 4$. In support of $\mathrm{H} 1$, relationship benefits positively and significantly impact the feelings of gratitude $(\beta=0.204, \mathrm{p}>0.05)$. Moreover, in support of $\mathrm{H} 2$, positive significant impact of relationship benefits on reciprocity $(\beta=0.361, \mathrm{p}>0.001)$; H3, positive significant impact of relationship investments on feelings of gratitude $(\beta=$ $0.572, \mathrm{p}>i 0.001)$; and $\mathrm{H} 5$, positive significant impact of feelings of gratitude on norms of reciprocity $(\beta=0.433, \mathrm{p}>0.001)$.

Figure 2

(PLS-SEM Output)

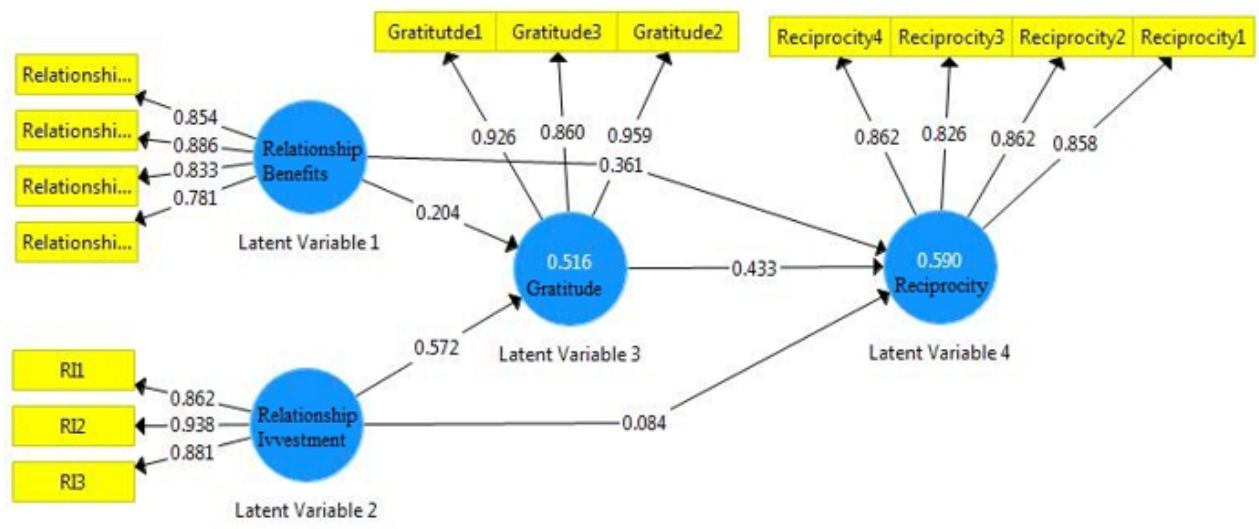

Table 5

Direct Effect

\begin{tabular}{lccc}
\hline Path & Beta Value & T Statistics & P values \\
\hline Relationship Benefits $\rightarrow$ Gratitude & 0.204 & 2.014 & 0.044 \\
Relationship Investments $\rightarrow$ Gratitude & 0.572 & 6.976 & 0.000 \\
Relationship Benefits $\rightarrow$ Reciprocity & 0.361 & 4.293 & 0.000 \\
Relationship Investments $\rightarrow$ Reciprocity & 0.084 & 0.753 & 0.452 \\
Gratitude $\rightarrow$ Reciprocity & 0.433 & 4.534 & 0.000 \\
\hline
\end{tabular}

Table 6

Specific Indirect Effect

\begin{tabular}{lccc}
\hline Path & Beta Value & T Statistics & P values \\
\hline Relationship Benefits $\rightarrow$ Gratitude $\rightarrow$ Reciprocity & 0.088 & 1.942 & 0.052 \\
Relationship Investments $\rightarrow$ Gratitude $\rightarrow$ Reciprocity & 0.248 & 3.656 & 0.000 \\
\hline
\end{tabular}

H6 and H7 propose mediation in the structural model. H6 postulate that, customer's 
feelings of gratitude mediate the positive influence of relationship benefits on norms of reciprocity; whereas, H7 suggest the mediation of customer's feeling of gratitude between relationship investments and norms of reciprocity. Relationship benefits positively and significantly impact the norms of reciprocity $(\beta=0.361, \mathrm{p}>0.001)$, moreover the indirect

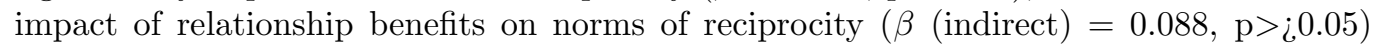
found insignificant, which means there is no mediation role of customer's feelings of gratitude between relationship benefits and norms of reciprocity, and H6 is rejected. Relationship investments is not directly related to norms of reciprocity $(\beta=0.084, \mathrm{p}>0.05)$. However, relationship investments indirectly via mediated path of customer's feelings of gratitude found positively significant $((\beta$ (indirect) $=0.248, \mathrm{p}>0.001)$; this means, customer's feelings of gratitude completely mediates between relationship investments and norms of reciprocity. Hence, $\mathrm{H} 7$ is accepted. The tabular presentation of hypotheses results are displayed in table- 7 .

\begin{tabular}{llc} 
Table 7 & \multicolumn{1}{c}{ Hypothesized relationship } & Results \\
\hline & \multicolumn{1}{c}{ Supported } \\
H1 & Relationship Benefits $\rightarrow$ Feelings of customer Gratitude & Supported \\
H2 & Relationship Benefits $\rightarrow$ Norms of Reciprocity & Supported \\
H3 & Relationship Investments $\rightarrow$ Feelings of customer Gratitude & Not Supported \\
H4 & Relationship Investments $\rightarrow$ Norms of Reciprocity & Supported \\
H5 & Feelings of customer Gratitude $\rightarrow$ Norms of Reciprocity & Not Supported \\
H6 & Relationship Benefits $\rightarrow$ Feelings of customer Gratitude $\rightarrow$ Norms of Reciprocity & Supported \\
H7 & Relationship Investments $\rightarrow$ Feelings of customer Gratitude $\rightarrow$ Norms of Reciprocity & S
\end{tabular}

Finally, the model significantly explains the proposed relationships. The explained variance in examined variables provides support for overall proposed conceptual model. Specifically, the model explains $51.60 \%$ variance in customer's feelings of gratitude and $59.0 \%$ of variance in norms of reciprocity. The explained variance is assessed with R2 values. PLS-SEM output is available in fig- 2 for additional clarity and validity of results and proceeding research implications.

\section{Discussion}

By applying, interpersonal relationship marketing perspective with dyadic data, the proposed conceptual model is tested. Relationship benefits as customer focal antecedent and relationship investments as seller focal antecedent are examined; do they lead to norms of reciprocity via customer feelings of gratitude as mediator.

\section{Theoretical Implications}

The research validates and extend the interpersonal relationship marketing model by Palmatier et al. (2009) based on interpersonal relationship theory. Interpersonal relationship marketing theory is extended by incorporating the interpersonal interaction reinforcement theories of friendship (Perlman \& Fehr, 1986). Customer feelings of gratitude are analyzed with reciprocity, and outline the reciprocity as outcome variable and gratitude as mediator. This help to overcome the conceptual ambiguities in understanding the rules 
and norms of exchange proposed by Cropanzano and Mitchell (2005), furthermore, this advocates the development of relationship is in stages or ladder form.

This research evaluates the customer's feelings of gratitude in both customer focal antecedents (relationship benefits) and seller focal antecedents (relationship investments) and links to reciprocity. The research finds the different paths for both relationship benefits and relationship investments. The seller's relationship investments are found to be more important because it creates the emotional attachment and debt (in form of gratitude) that may cause to maintain sustainable customer relationship and customer try to pay that particular emotional debt that continues the buyer-seller relationship.

The dyadic dataset from multiple sectors with variance based PLS-SEM strengthen and extend the methodological support for interpersonal relationship marketing theory and model testing.

In general, it is expected people to feel less gratitude in response to benefits from relationship partners in an established relationship. The results are consistent with notion that, the people try to return the same benefits and in case of unexpected benefit or sense of investment from the other partner in the relationship will make them feel more gratitude and he/she try to return the same gratitude.

\section{Managerial Implications}

This research offers multiple managerial implications for sellers and marketing practitioners. It helps to understand the dynamics of sustainable relationship between buyer-seller in a comprehensive way, through responses recorded from both parties (buyer and seller) and examined in a rigorous manner. The research applies theoretical support of interpersonal interaction to build and maintain friendship in interpersonal relationship marketing perspective, therefore, this research helps to understand how human-like relationship (Ma et al., 2017) build between buyer and seller.

With emotionally committed relationship with buyers; sellers can enhance their objective performance with cross selling and up selling (Palmatier et al., 2009). The rationale behind this cross selling and up selling is that, emotionally committed customer is likely to act in accordance to seller consultation and advice. The emotionally motivated customer lost its rationality. So, the seller may take advantage of this situation by cross selling and up selling to the customer.

Sellers must needs to create sense of realization among customer through their message and customer service activities that firm is investing on the relationship with them. The positive thought in customers about the seller investments will compel customers to be grateful to seller. Moreover, they will reciprocate with seller. This sense of realization need to visible in their communication and message to customers.

Reciprocation of gratitude will generate loyalty and strengthen the relationship between sellers and buyers. The benefits provided to customers directly reciprocate; whereas, the investments from sellers built emotional ties with customers that create the emotional debts. Furthermore, when emotional debt is paid (this happen in a cyclic form (Palmatier et al., 2009) in form of customer reciprocity and long-term relationship takes birth with customers with sellers investments on relationship. 
The behavior of the customers is more predictable that are under emotional debt. Such customers come with lesser complaints and service demands. Consequently, customers spread positive words of mouth about the sellers.

\section{Limitations and Future Research Directions}

Similar to previous good researches, this research also has some limitations. First limitation is cross-sectional nature of dyadic data. Using, cross sectional data may lead to inflated response due to number of factors e.g., bad mood of respondent. Second, the customer focal antecedents and seller focal antecedents are assessed; however, the other dyadic constructs may present the different picture of relationship. Lastly, there are number control factors applied to this research, whereas the incorporation of such variables in the assessment may leads to different results and implications. This research opens multiple new research horizons. First, for generalization of this proposed conceptual model, it needs empirical testing in other contexts. This model may also be empirically validated to a specific sector e.g., hospitality services. Secondly, the future research may use triadic data set e.g., buyer, seller, employees, and financial data. Third, the future research need to incorporate the other antecedents of customer focal and seller focal antecedents e.g., customer orientations. Lastly, the future research may incorporate the other customer psychological feeling and behavior in buyer and seller relationship dyad e.g., customer intimacy.

\section{Conclusion}

In conclusion, customer focal and seller focal antecedents are examined with mediating role of customers feeling of gratitude to develop reciprocity. Data is collected from both buyers and sellers from multiple sectors. Partial least square structural equation modeling (PLS-SEM) is used to test the dyadic data set. This applied interpersonal relationship marketing model and interpersonal attraction to study the proposed model. The results provide support for proposed model. Theoretically, interpersonal relationship marketing model is extended by incorporating reinforcement theories of interpersonal attraction. From managerial perspective this research helps managers to understand the importance of seller focal and customer focal antecedents in reciprocal customer behavior. 


\section{References}

Ahearne, M., MacKenzie, S. B., Podsakoff, P. M., Mathieu, J. E., \& Lam, S. K. (2010). The role of consensus in sales team performance. Journal of Marketing Research, $47(3), 458-469$.

Akter, S., Fosso Wamba, S., \& Dewan, S. (2017). Why pls-sem is suitable for complex modelling? An empirical illustration in big data analytics quality. Production Planning E Control, 28(11-12), 1011-1021.

Bagozzi, R. P. (1995). Reflections on relationship marketing in consumer markets. Journal of the Academy of Marketing science, 23(4), 272-277.

Becker-Olsen, K. L., \& Hill, R. P. (2006). The impact of sponsor fit on brand equity: The case of nonprofit service providers. Journal of Service Research, 9(1), 73-83.

Brun, I., Rajaobelina, L., \& Ricard, L. (2016). Online relationship quality: Testing an integrative and comprehensive model in the banking industry. Journal of Relationship Marketing, 15(4), 219-246.

Chao, C.-C., Chen, H.-T., \& Yeh, T.-L. (2015). A comprehensive relationship marketing model between airlines and travel agencies: The case of Taiwan. Journal of Air Transport Management, 47, 20-31.

Cronbach, L. J., \& Meehl, P. E. (1955). Construct validity in psychological tests. Psychological Bulletin, 52(4), 281-302.

Cropanzano, R., \& Mitchell, M. S. (2005). Social exchange theory: An interdisciplinary review. Journal of Management, 31(6), 874-900.

Debnath, R., Datta, B., \& Mukhopadhyay, S. (2016). Customer relationship management theory and research in the new millennium: Directions for future research. Journal of Relationship Marketing, 15(4), 299-325.

Dewani, P. P., Sinha, P. K., \& Mathur, S. (2016). Role of gratitude and obligation in long term customer relationships. Journal of Retailing and Consumer Services, 31, $143-156$.

Finch, D., O'Reilly, N., Hillenbrand, C., \& Abeza, G. (2015). Standing on the shoulders of giants: An examination of the interdisciplinary foundation of relationship marketing. Journal of Relationship Marketing, 14(3), 171-196.

Fornell, C., \& Larcker, D. F. (1981). Structural equation models with unobservable variables and measurement error: Algebra and statistics. Sage Publications Sage CA: Los Angeles, CA.

Griffith, D. A., Harvey, M. G., \& Lusch, R. F. (2006). Social exchange in supply chain relationships: The resulting benefits of procedural and distributive justice. Journal of Operations Management, 24(2), 85-98.

Gwinner, K. P., Gremler, D. D., \& Bitner, M. J. (1998). Relational benefits in services industries: the customer's perspective. Journal of the Academy of Marketing Science, 26(2), 101-114.

Hair, J. F., Ringle, C. M., \& Sarstedt, M. (2011). PLS-SEM: indeed a silver bullet. Journal of Marketing theory and Practice, 19(2), 139-152.

Hair, J. F., Sarstedt, M., Ringle, C. M., \& Mena, J. A. (2012). An assessment of the use of partial least squares structural equation modeling in marketing research. Journal 
of the Academy of Marketing Science, 40(3), 414-433.

Harmeling, C. M., Palmatier, R. W., Fang, E., \& Wang, D. (2017). Group marketing: Theory, mechanisms, and dynamics. Journal of Marketing, 81(4), 1-24.

Hasan, S. F., Lings, I., Neale, L., \& Mortimer, G. (2014). The role of customer gratitude in making relationship marketing investments successful. Journal of Retailing and Consumer Services, 21(5), 788-796.

Hollmann, T., Jarvis, C. B., \& Bitner, M. J. (2015). Reaching the breaking point: a dynamic process theory of business-to-business customer defection. Journal of the Academy of Marketing Science, 43(2), 257-278.

Hoppner, J. J., Griffith, D. A., \& White, R. C. (2015). Reciprocity in relationship marketing: A cross-cultural examination of the effects of equivalence and immediacy on relationship quality and satisfaction with performance. Journal of International Marketing, 23(4), 64-83.

Huang, M.-H. (2015). The influence of relationship marketing investments on customer gratitude in retailing. Journal of Business Research, 68(6), 1318-1323.

Hütten, A. S., Salge, T. O., Niemand, T., \& Siems, F. U. (2018). Advancing relationship marketing theory: Exploring customer relationships through a process-centric framework. AMS Review, 8(1-2), 39-57.

Jin, N., Line, N. D., \& Yoon, D. (2018). Understanding the role of gratitude in building quality relationships. Journal of Hospitality Marketing 85 Management, 27(4), 465485.

Kenny, D. A., Kashy, D. A., \& Cook, W. L. (2006). Dyadic data analysis. New York: Guilford.

Kozlenkova, I. V., Palmatier, R. W., Fang, E., Xiao, B., \& Huang, M. (2017). Online relationship formation. Journal of Marketing, 81(3), 21-40.

Lambert, N. M., Graham, S. M., \& Fincham, F. D. (2009). A prototype analysis of gratitude: Varieties of gratitude experiences. Personality and Social Psychology Bulletin, 35(9), 1193-1207.

Liu, Y.-H. S., Deligonul, S., Cavusgil, E., \& Chiou, J.-S. (2018). Always trust in old friends? Effects of reciprocity in bilateral asset specificity on trust in international b2b partnerships. Journal of Business Research, 90, 171-185.

Lussier, B., \& Hartmann, N. N. (2017). How psychological resourcefulness increases salesperson's sales performance and the satisfaction of their customers: Exploring the mediating role of customer-oriented behaviors. Industrial Marketing Management, 62, 160-170.

Ma, L. K., Tunney, R. J., \& Ferguson, E. (2017). Does gratitude enhance prosociality? a meta-analytic review. Psychological Bulletin, 143(6), 601-635.

MacKinnon, D. P., Lockwood, C. M., \& Williams, J. (2004). Confidence limits for the indirect effect: Distribution of the product and resampling methods. Multivariate Behavioral Research, 39(1), 99-128.

Morgan, R. M., \& Hunt, S. D. (1994). The commitment-trust theory of relationship marketing. Journal of Marketing, 58(3), 20-38.

Palmatier, R. W., Jarvis, C. B., Bechkoff, J. R., \& Kardes, F. R. (2009). The role of customer gratitude in relationship marketing. Journal of Marketing, 73(5), 1-18. 
Paswan, A. K., Hirunyawipada, T., \& Iyer, P. (2017). Opportunism, governance structure and relational norms: An interactive perspective. Journal of Business Research, 77, 131-139.

Perlman, D., \& Fehr, B. (1986). Theories of friendship: The analysis of interpersonal attraction. Springer: New York.

Pervan, S. J., Bove, L. L., \& Johnson, L. W. (2009). Reciprocity as a key stabilizing norm of interpersonal marketing relationships: Scale development and validation. Industrial Marketing Management, 38(1), 60-70.

Podsakoff, P. M., MacKenzie, S. B., Lee, J.-Y., \& Podsakoff, N. P. (2003). Common method biases in behavioral research: A critical review of the literature and recommended remedies. Journal of Applied Psychology, 88(5), 879.

Reynolds, K. E., \& Beatty, S. E. (1999). Customer benefits and company consequences of customer-salesperson relationships in retailing. Journal of Retailing, 75(1), 11-32.

Rungtusanatham, M., Miller, J., \& Boyer, K. (2014). Theorizing, testing, and concluding for mediation in SCM research: tutorial and procedural recommendations. Journal of Operations Management, 32(3), 99-113.

Sheth, J. N., \& Parvatiyar, A. (1995). The evolution of relationship marketing. International Business Review, 4(4), 397-418.

Vargo, S. L., \& Lusch, R. F. (2004). Evolving to a new dominant logic for marketing. Journal of Marketing, 68(1), 1-17.

Verma, V., Sharma, D., \& Sheth, J. (2016). Does relationship marketing matter in online retailing? a meta-analytic approach. Journal of the Academy of Marketing Science, 44(2), 206-217.

Wood, A. M., Froh, J. J., \& Geraghty, A. W. (2010). Gratitude and well-being: A review and theoretical integration. Clinical Psychology Review, 30(7), 890-905. 